\title{
Numerical and Experimental Evaluation of Mechanical and Ring Stiffness Properties of Preconditioning Underground Glass Fiber Composite Pipes
}

\author{
Mohamed K. Hassan 1,2,*(D), Ahmed F. Mohamed 1,3,*, Khalil Abdelrazek Khali1 4,5,*(D) \\ and Mohammed Y. Abdellah 1,6,*(D) \\ 1 Mechanical Engineering Department, College of Engineering and Islamic Architecture, \\ Umm Al-Qura University, Makkah 21421, Saudi Arabia \\ 2 Production Engineering \& Design Department, Faculty of Engineering, Minia University, Minia 61111, Egypt \\ 3 Mechanical Engineering Department, Faculty of Engineering, Sohag University, Sohag 82524, Egypt \\ 4 Department of Mechanical and Nuclear Engineering, College of Engineering, University of Sharjah, \\ Sharjah 27272, United Arab Emirates \\ 5 Materials Department, Faculty of Energy Engineering, Aswan University, Aswan 81521, Egypt \\ 6 Mechanical Engineering Department, Faculty of Engineering, South Valley University, Qena 83521, Egypt \\ * Correspondence: mkibrahiem@uqu.edu.sa (M.K.H.); afmohamed@uqu.edu.sa (A.F.M.); \\ kabdelmawgoud@sharjah.ac.ae (K.A.K.); myahmad@uqu.edu.sa (M.Y.A.)
}

\section{check for} updates

Citation: Hassan, M.K.; Mohamed, A.F.; Khalil, K.A.; Abdellah, M.Y.

Numerical and Experimental

Evaluation of Mechanical and

Ring Stiffness Properties of

Preconditioning Underground Glass Fiber Composite Pipes. J. Compos. Sci. 2021, 5, 264. https://doi.org/ $10.3390 /$ jcs5100264

Academic Editor: Stelios

K. Georgantzinos

Received: 8 September 2021

Accepted: 8 October 2021

Published: 10 October 2021

Publisher's Note: MDPI stays neutral with regard to jurisdictional claims in published maps and institutional affiliations.

Copyright: (c) 2021 by the authors. Licensee MDPI, Basel, Switzerland. This article is an open access article distributed under the terms and conditions of the Creative Commons Attribution (CC BY) license (https:// creativecommons.org/licenses/by/ $4.0 /)$.

\begin{abstract}
The mechanical and ring stiffness of glass fiber pipes are the most determining factors for their ability to perform their function, especially in a work environment with difficult and harmful conditions. Usually, these pipes serve in rough underground environments of desert and petroleum fields; therefore, they are subjected to multi-type deterioration and damage agents. In polymers and composite materials, corrosion is identified as the degradation in their properties. In this study, tension and compression tests were carried out before and after preconditioning in a corrosive agent for 60 full days to reveal corrosion influences. Moreover, the fracture toughness is measured using a standard single edge notch bending. Ring stiffness of such pipes which, are considered characteristic properties, is numerically evaluated using the extended finite element method before and after preconditioning. The results reported that both tensile and compressive strengths degraded nearly more than $20 \%$. Besides the fracture toughness decrease, the stiffness ring strength is reduced, and the finite element results are in good agreement with the experimental findings.
\end{abstract}

Keywords: composite; pipe; fracture toughness; damage; ring stiffness infrastructure industries

\section{Introduction}

Polymer-based composite materials have several important properties, such as lightweight, specific Young's modulus, and specific impact resistance, making them suitable for use in a wide range of industrial and aerospace applications [1,2]. In various environments, the stress corrosion and failure caused by these reinforced plastics were investigated [3-6]. Glass fiber reinforced plastic is a structural material made of short or long glass fibers and a thermosetting resin. Quartz particles are sometimes used as reinforcement by combining them with epoxy resin, forming the composite matrix. This matrix and numerous laminates of glass fiber reinforced polymer are used to make glass fiber reinforced pipes. Plastic composite pipes are a cost-effective alternative to metallic pipes. Metallic pipes are not permitted in applications where corrosion, weight, and environmental impact are critical. Fiberglass reinforced pipes have many applications, including pressure piping and water transfer above and below ground [7-10].

Farshad [11] performed compression tests on the fiberglass pipes and conditioned the pipe materials before running the tests in water at room temperature. Throughout the test, sample deflection was measured in relation to time. The findings indicated that the 
conditioned environment reduces the strength of these materials. In a related study by Nishizaki [12], the effect of water on durability was investigated. It was determined that the flexural strength of GRP is lower when immersed than when only at atmospheric humidity. Bergman [13] was able to handle plastic corrosion for chlorine dioxide, sodium chlorate, and chlorine in various environments. The differences between metal and plastic corrosion were compared to obtain typical reasons for using plastics in the processing industry and specific environments for plastic applications. Furthermore, after reviewing the corrosion behavior of GRP pipes, Hojo et al. [14] identified three types of corrosion: surface reaction, formation of a corrosive layer, and penetration-induced corrosion. Farshad and Nicola [15] tested unsaturated fiberglass reinforced polyester (GRP) pipe rings for long-term stress corrosion. In the lower region of the ring, these specimens were treated with $5 \%$ sulfuric acid. Compared to the non-acidic section of the same sample, the deformability of the tested section in the acidic environment was reduced by approximately $75 \%$.

It was discovered that there is a direct relationship between specimen densities and dimensional accuracy with orientation [16]. In addition, the angular orientation caused significant anisotropy in the fracture toughness of single edge notch samples. The effects of seawater aging and curing on polymer composite cylinders used as marine structures were studied. Fully cured composite cylinders outperformed partially cured composite cylinders in terms of mechanical properties. Furthermore, aging in seawater improved hoop strength and stiffness but had no effect on radial strength. Similarly, the hardness and density of the same cylinders were investigated in the presence of salty water and found to change [17]. In addition, the effect of seawater on steel pipes rehabilitated with layers of fiberglass and epoxy was studied [18]. The hoop strength of the pipes being repaired increased before and after immersion, indicating that a thicker composite repair is required for complete rehabilitation. The association between the structural properties of the shell and the end bearing capacity (UBC) of fiberglass-reinforced mortar pipes (GRP) was simulated [19]. In a growing pipeline, the proportion of the size of the fibers and the ratio of the volume of the spirally wound layer increased, but UBC increased with the layers of tubules. It has been reported that the fracture and mechanical properties of GRP pipes degrade after immersion in a corrosive medium (solution of sodium chloride in water) $[20,21]$. This deterioration was attributed to corrosion caused by the use of a corrosive medium. On the other hand, the effect of thermal aging on the compression behavior of interlocking polymer network composites reinforced with fiberglass was discussed. As the temperature rose and the aging period progressed, the strength of these pipes decreased slightly.

It is observed that all previous work did not deal with fracture toughness and impact strength, besides the ring stiffness properties under a harsh underground environment. Therefore, the main objectives of this study are to investigate and fully comprehend the behavior of glass fiber reinforced epoxy pipes during service in the harsh underground environment of the petroleum field. Consequently, tensile, compression, single edge notch bending, and Charpy impact tests were performed before and after preconditioning in drag water of a petroleum environment field. The ring stiffness properties were numerically measured using an extended finite element method and compared to other experimental work to validate the model with one before preconditioning.

\section{Experimental Work}

It is well established that standard tests are performed on samples with standard dimensions when determining mechanical or fracture properties. When evaluating the behavior and properties of materials under specific operational conditions, tests are carried out under the same conditions and concerning previous similar experiments. In our case, the test was performed on a portion of the material composed under the same harmful and/or harsh operating conditions to demonstrate the extent of the condition's effect on those materials. entire domain [15,22-24]. 


\subsection{Materials and Methods}

According to the values shown in Figure 1 and listed in Table 1, the present study used glass fiber-reinforced polymer pipes with a heterogeneous structure consisting of random matt, roving, unsaturated polyester resin, and sand. Unsaturated polyester resin is environmentally and chemically resistant, and it also bonds the fiber in the pipe structure. Unsaturated polyesters are less expensive than other resins used to produce GRP pipes, but they offer only a slight increase in strength and chemical resistance. It is frequently a costeffective option for less demanding, low-pressure service. The glass fiber composite pipes were created using the widely used filament winding technology. GRP has a complicated structure with inner and outer surface layers. The barrier and chop layers are followed by the structure layers in the outer and inner surfaces, with quartz sand placed between for a complete description of the manufacturing process, refer to [18]. The composite material is primarily determined by fiber geometry, lay-up thickness, fiber pretension, and manufacturing process quality. These constituent compositions were obtained using the ASTM D3171-99 standard [25] and the ignition removal technique. These pipes are used in chemical wastewater pipelines in the petroleum industry. The elastic properties of the glass fiber composite pipes (GRP) are listed in Table 2. the pipes used in the present study; are taken from situ and were in service for some time.

In Figure $1 b$, it is noted that the percentage of chlorine gas in petroleum wastewater is greater than that of solid impurities $(\mathrm{S}, \mathrm{Ca}, \mathrm{Br}$, and $\mathrm{Ag})$. The presence of $\mathrm{Cl}$ gas in wastewater increases corrosion [14] and erosion because it acts as an active agent by chemically reacting with the organic components of the composite pipe, such as resin, glass fiber, and quartz particles.

Table 1. Composition of GFR pipes [20,26].

\begin{tabular}{lccccc}
\hline \multicolumn{1}{c}{ Constituents } & Average \% & Viscosity/cp.25 ${ }^{\circ} \mathbf{C}$ & $\begin{array}{c}\text { Thermal Deformation } \\
\text { Temperature/ } /{ }^{\circ} \mathbf{C}\end{array}$ & $\begin{array}{c}\text { Tensile Strength } \\
/ \mathbf{M P a}\end{array}$ & $\begin{array}{c}\text { Specific Density } \\
\left(\mathbf{g} / \mathbf{c m}^{3}\right)\end{array}$ \\
\hline $\begin{array}{l}\text { Thermosetting } \\
\text { unsaturated } \\
\text { polyester (Matrix) }\end{array}$ & $30.2 \%$ & 400 & 70 & 65 & 1.12 \\
$\begin{array}{l}\text { Roving } \\
\text { matt } \\
\text { sand }\end{array}$ & 11.8 & - & - & & \\
\hline
\end{tabular}

Table 2. Elastic properties of GRP [24].

\begin{tabular}{ccccccc}
\hline Properties & $\mathrm{E}_{\mathbf{1}}(\mathrm{GPa})$ & $\mathrm{E}_{\mathbf{2}}(\mathrm{GPa})$ & $\boldsymbol{v}_{\mathbf{1 2}}$ & $\mathrm{G}_{\mathbf{1 2}}(\mathrm{GPa})$ & $\mathrm{G}_{\mathbf{1 3}}(\mathrm{GPa})$ & $\mathrm{G}_{\mathbf{2} 3}(\mathrm{GPa})$ \\
\hline value & 100 & 9 & 0.3 & 3.2 & 3.2 & 4 \\
\hline
\end{tabular}

\subsection{Preconditioning Procedures}

The conditioning procedures are performed by immersion the test samples into a corrosive agent of wastewater taken from the petroleum field. The specimens were put in a wide container, as shown in Figure 2, in a field with sewage. The composition, illustrated previously in Figure 1, of a high amount of chlorine gas, is responsible for corrosion. They had a lousy effect on the pipe's material in a harsh environment. The specimens were left in the corrosive solution for 60 days at a room temperature range. Then the sample was left to dry from water then testing was carried out. 
a)

outer surface

)

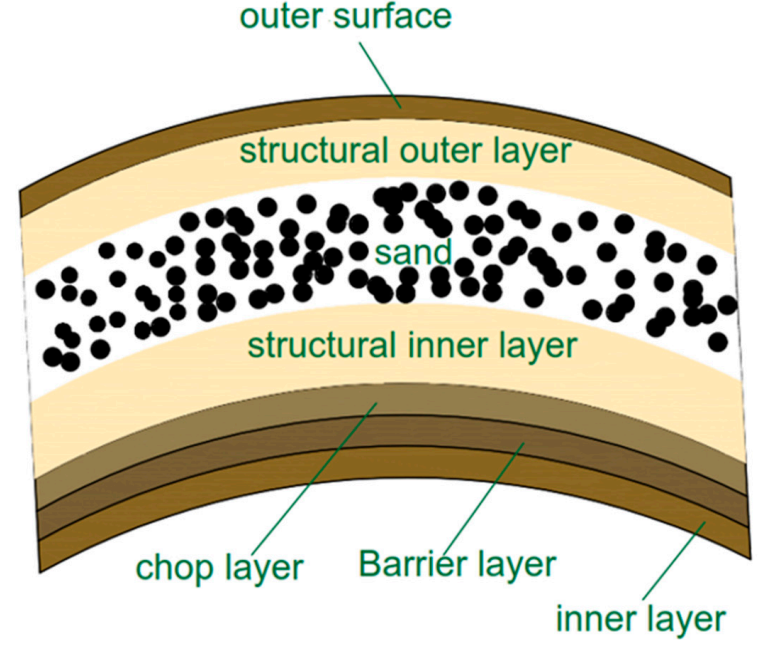

b)

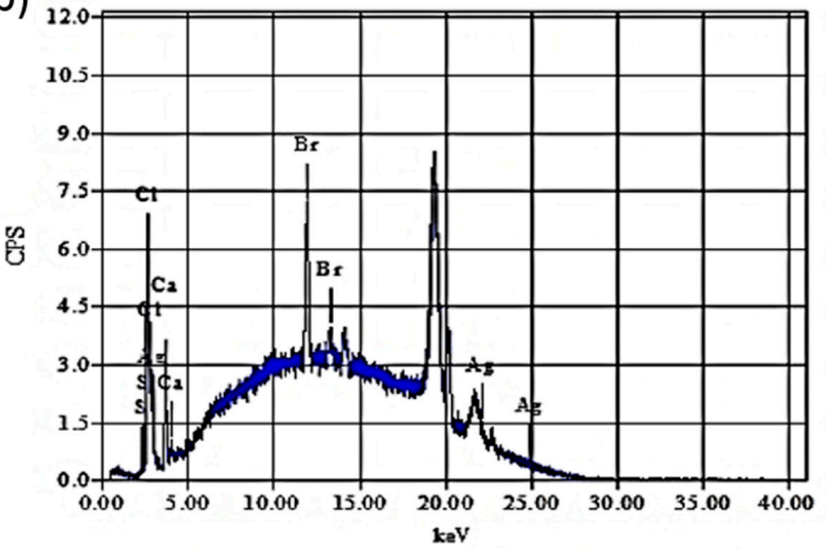

$\begin{array}{cccccccc}\text { Element } & \text { Line type } & \text { Energy } & \mathrm{ms} \% & \text { mol\% } & \mathrm{K} & \mathrm{net} & \text { Error \% } \\ \mathrm{S} & \mathrm{K} & 2.31 & 4.7234 & 6.16665 & 0.0018651 & 334 & 1.2631 \\ \mathrm{Cl} & \mathrm{K} & 2.62 & 58.794201 & 69.4201 & 0.0194530 & 7868 & 1.3922 \\ \mathrm{Ca} & \mathrm{K} & 3.69 & 15.0785 & 15.7482 & 0.0029557 & 4484 & 0.4507 \\ \mathrm{Br} & \mathrm{K} & 11.91 & 2.6441 & 1.3852 & 0.0024013 & 10392 & 0.0488 \\ \mathrm{Ag} & \mathrm{L} & 2.98 & 18.7594 & 7.2800 & 0.0065527 & 1685 & 2.0120\end{array}$

Figure 1. GRP wastewater system; (a) GRP schematic [20] and (b) chemical analysis of a wastewater petroleum sample.

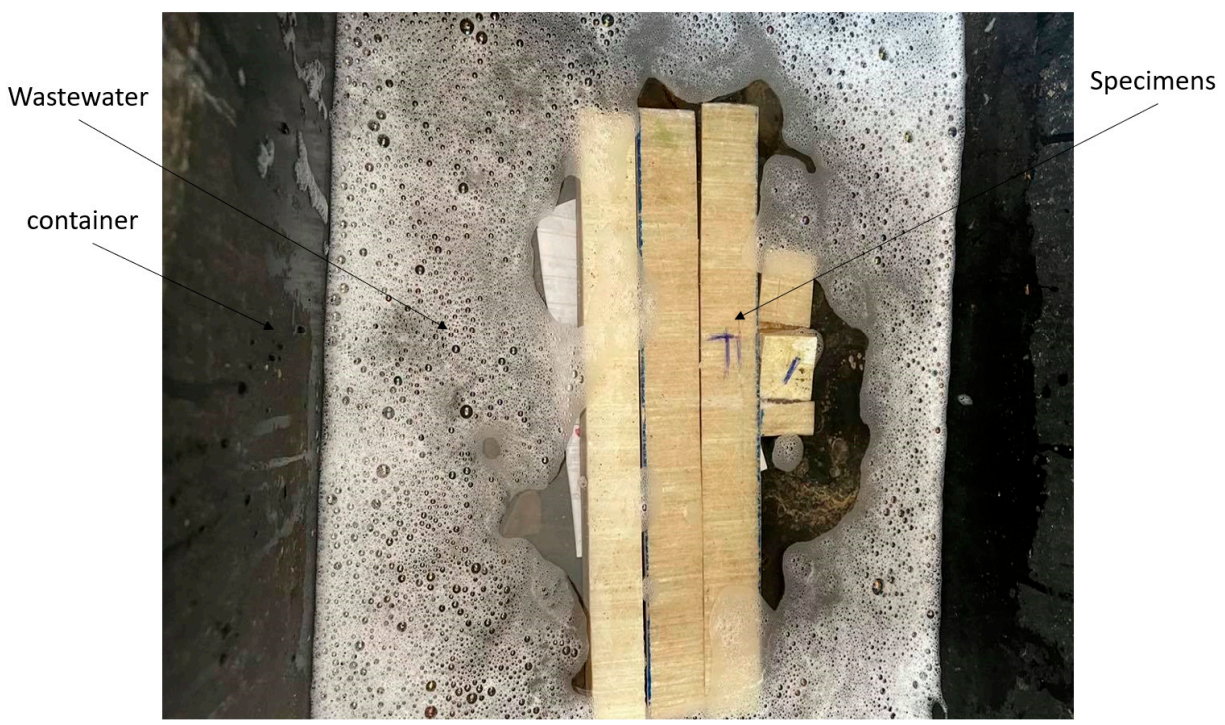

Figure 2. Chemical treatment to preconditioning the GRP pipes material. 


\subsection{Mechanical Testing}

Tension and compression tests were carried out on specimens made from glass fiber reinforced polymer pipe wall thicknesses $(\mathrm{DN}=520.7 \mathrm{~mm}$ and $13 \mathrm{~mm})$. These tests were performed in accordance with ASTM D3039 [27] and ASTM D3410 [28] standards for tension and compression, respectively, on a computer control electromechanically universal testing machine (machine model WDW-100- Jinan Victory Instrument Co. Ltd, China) [29] with a load capacity of $100 \mathrm{kN}$ and a controlled speed of $2 \mathrm{~mm} / \mathrm{min}$. The standard specimen geometry for tension and compression is shown in Figures 3 and 4, respectively. The compressive load was applied in both the longitudinal and transverse directions (see Figure 4a) and (see Figure 4b), respectively). These tests were repeated for specimens immersed into a petroleum field of wastewater for 60 days at room temperature. Each test required the use of five samples for measuring their average.

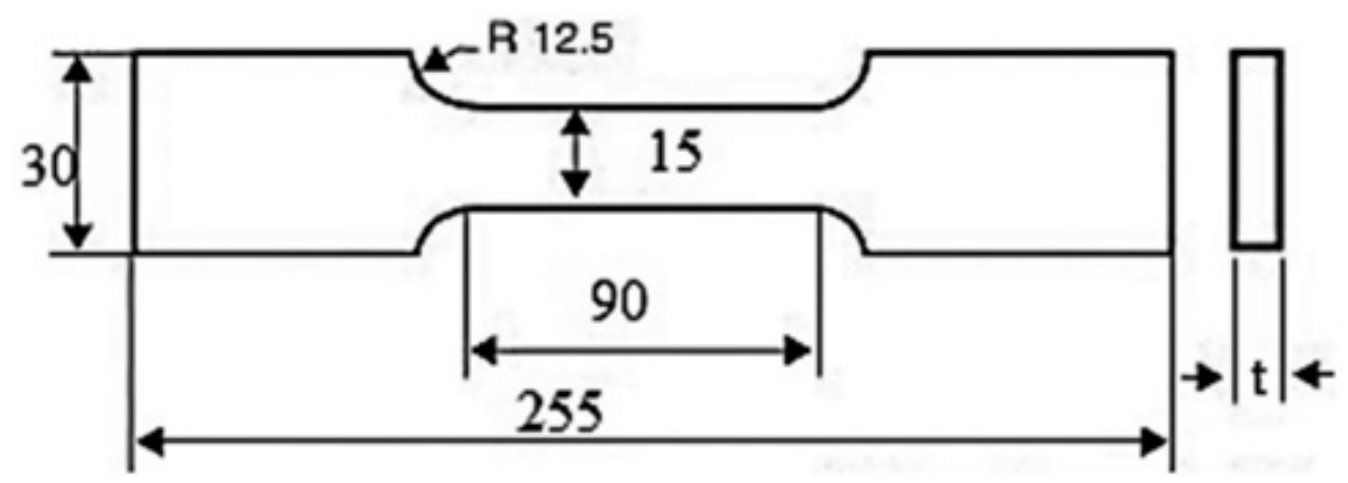

Figure 3. Geometry of tensile test specimens.

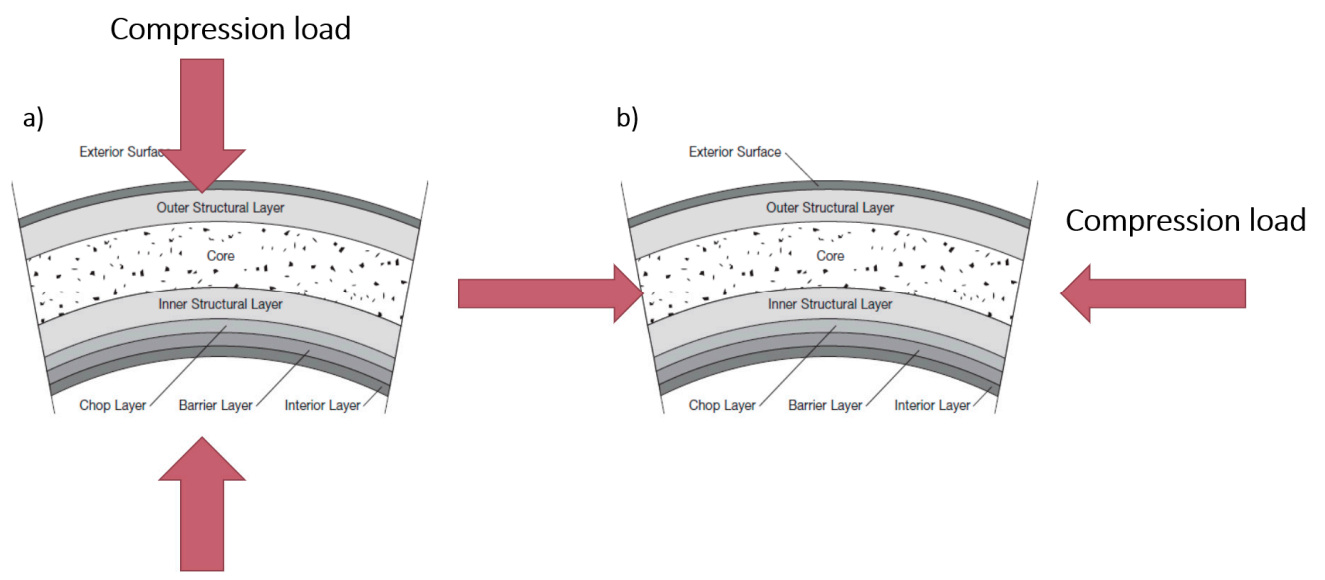

Figure 4. Compression loading direction is either (a) transverse or (b) longitudinal.

\subsection{Fracture Toughness Test}

The fracture toughness of these composite materials is emphasized because, in the event of a crack, it allows water to infiltrate and absorb into GRP pipes, causing harmful corrosion and deterioration of mechanical properties. As a result, fracture toughness has emerged as an essential and determining factor of pipe properties, and it must be measured. According to Anderson et al. [30], only one type of fracture toughness test is used to accomplish this. Measuring crack resistance is critical to halt deterioration and achieve good fracture toughness values. The single edge notch test specimen, shown in Figure $5 \mathrm{~b}$, was cut from the wall according to the dimensions specified in the ASTM D5045-14 standard [31], as shown in Figure 5a. The specimen has a thickness of $13 \mathrm{~mm}$ and a scaled mark on the face of the crack. A notch of about 45 percent of the beam width is formed in the middle of the beam span. After sharpening the root of the notch with a razor 
blade, the samples were pre-prepared to produce typical incisions $3-5 \mathrm{~mm}$ in length. The load-point is plotted against displacement as well.

a)

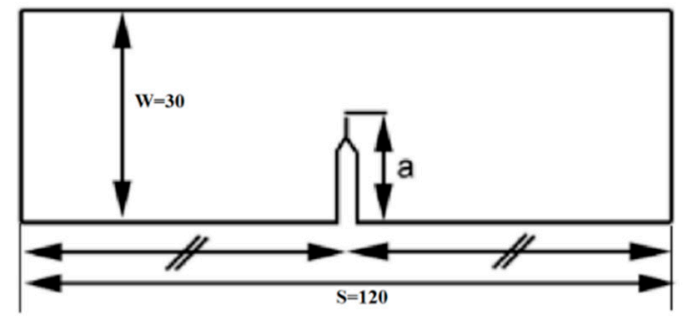

b)

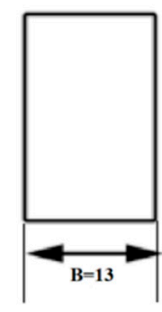

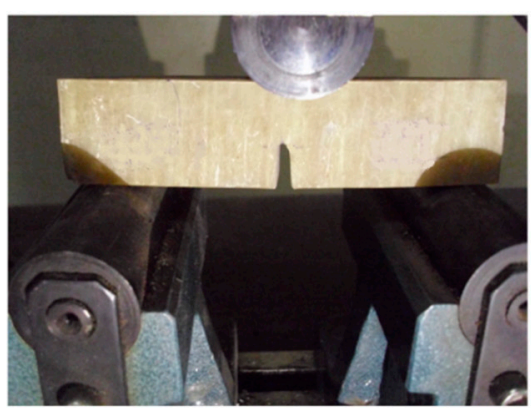

Figure 5. (a) specimen geometry, (b) test setup for single edge notch bending (SENB).

After the maximum load record, the fracture toughness $\left(K_{I C}\right)$ can be measured [32] using the following Equations;

$$
K_{I C} \frac{P S}{B W^{3 / 2}} f(a / w)
$$

where $f(a / w)$ is the correction factor and can be calculated as following [32];

$$
f(a / w)=2.9\left(\frac{a}{w}\right)^{0.5}-4.6\left(\frac{a}{w}\right)^{\frac{3}{2}}+21.8\left(\frac{a}{w}\right)^{\frac{5}{2}}-37.6\left(\frac{a}{w}\right)^{\frac{7}{2}}+38.7\left(\frac{a}{w}\right)^{\frac{9}{2}}
$$

where $(a)$ is a crack length, $(w)$ is specimen width, $(p)$ is bending load, $(B)$ is specimen thickness, and (s) is beam span.

Dynamic fracture toughness or impact fracture toughness can be measured using an ASTM D6110 [33] Charpy standard test pattern consisting of a metal (or other material) bar $(55 \times 10 \times 10 \mathrm{~mm})$ with a notch driven through one of the larger dimensions (see Figure $6 \mathrm{a}$ ). There are five specimens used. The pendulum impact tester is shown in Figure 6b.

a)

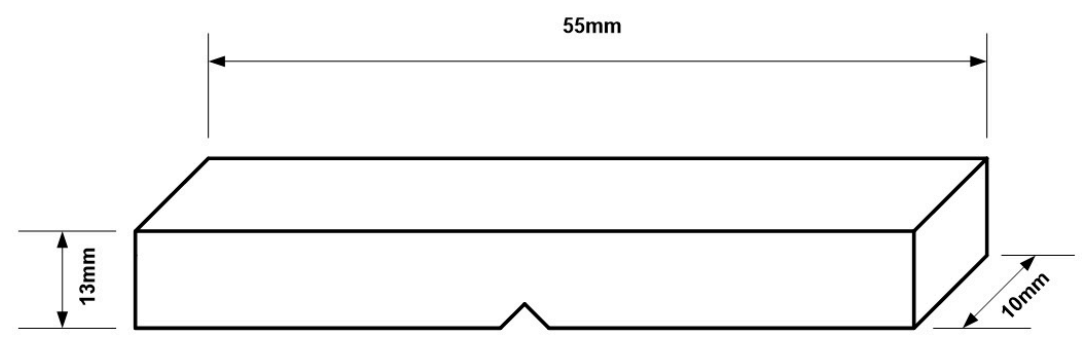

b)

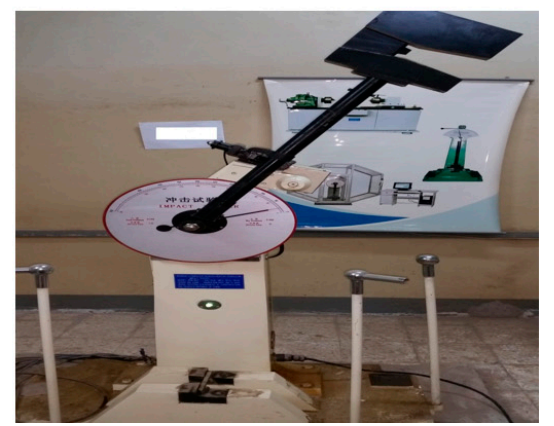

Figure 6. Charpy Impact test: (a) specimen geometry, (b) test setup.

\subsection{Finite Element Method of Compression Stress (Stiffness Ring of Cylinder Test)}

The stiffness ring of a cylinder is a physical characteristic of the pipe; it measures the resistance to ring deflection under external load. The following expression defines the stiffness ring of a pipe:

$$
S=\frac{E I}{d_{m}^{3}}
$$

where $(S)$ is ring stiffness, $(E)$ is young modulus, $(I)$ moment of inertia of pipes, and $\left(d_{m}\right)$ is mean pipe diameter.

Belytschko and Black [34] recently developed XFEM, the main idea of which is based on Melenk and Babuska [35], who used the concept of division of finite element units and the enrichment function. XFEM is distinguished because no network update is required to 
trace the crack path [36], reducing the need to interlace and re-interlace complex interruption surfaces. Because the crack extends around the tip of the fracture without reconnection or refinement, fracture analysis can be performed with high numerical precision; for a detailed description, see [37].

The 3D nonlinear elastic FEM is based on the primary, extended fracture method. A cylindrical domain $(520.7 \mathrm{~mm}$ diameter $\times 500 \mathrm{~mm})$ was created as a solid part (see Figure 7a). The reaction force and corresponding deflection are measured using extended finite element analysis. As shown in Figure 7a, the load is used as a constant displacement control for the upper surface of the cylinder while it is fixed at the two asymmetric ends of the cylinder. The 3D stress element type has an 8-node linear brick linear shape, reduced integration, and hourglass control (C3D8R) elements with an approximately hexagonal shape with a global size of 10 for region B were used in the domain. The total number of elements is 38,412; this is the best number chosen from three mesh densities investigated for mesh convergence (see Figure $7 \mathrm{~b}$ ). The maximum principal stress theory of failure was implemented with the mean stress of $30 \mathrm{MPa}$ and $8 \mathrm{MPa}$ for composite pipes without and with preconditioning in wastewater for 60 days. The damage evaluation criterion is the maximum fracture energy and the independent mixed mode that is applicable. The material used for the composite cylinder was based on DN 500 and SN 1000 [24].

Moreover, to create the failure propagation during the loading, a planar crack of (10 mm length) is inserted in the center of the cylinder region (A) (see Figure 7c). The element size in this region is defined as 5. These two values are derived from the standard tensile test results of the specimen of the curved pipe's layers before and after preconditioning. The equivalent young moduli are $35 \mathrm{GPa}$ and $10.5 \mathrm{GPa}$, and the fracture energy with linear softening was $185 \mathrm{~kJ} / \mathrm{m}^{2}$ and $129 \mathrm{~kJ} / \mathrm{m}^{2}$ for after and before, respectively. The study considers the load only over the outer surface, and there are no internal pressures applied. This study is to simulate the ring stiffness test introduced by Ref. [24].

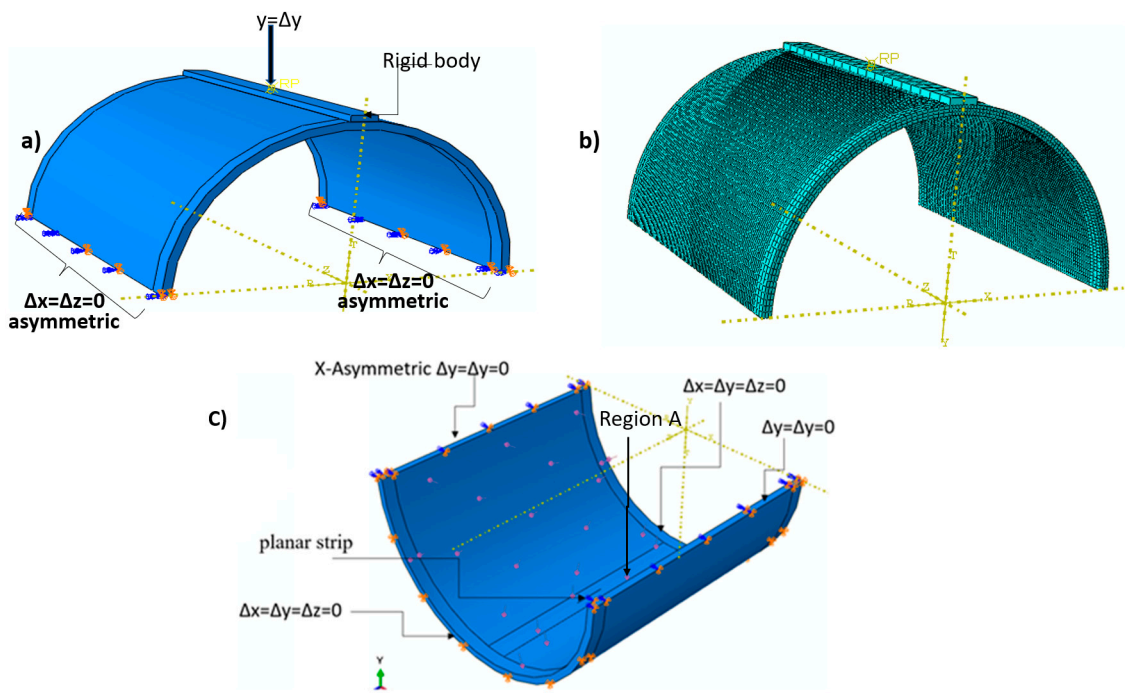

Figure 7. (a) Boundary condition, (b) mesh shape finite element domain, (c) domain with crack.

\section{Results}

\subsection{Mechanical Properties}

Figure 8 depicts the stress-strain relationship for tension test specimens before and after preconditioning. After preconditioning in corrosive water with increasing amounts of chlorine gas, the average tensile strength drops by nearly $50 \%$. It is approximately $18 \mathrm{MPa}$ with STDV equals $2 \mathrm{MPa}$; CV equals $11 \%$ before preconditioning and almost $8 \mathrm{MPa}$ with STDV $1 \mathrm{MPa}$ and CV equals $11.7 \%$ after preconditioning. This is due to hydro stress caused by moisture expansion coefficients in the polymer composite. Because of the material's thermoelastic and hydroelastic inhomogeneity and anisotropy, interlaminar and intralaminar stresses form. The net tension failure mode is depicted in Figure 9. 
Preconditioning also affects the material's Young's modulus, resulting in a decrease of nearly $70 \%$. The fracture behavior, as seen in microstructure examination, includes fiber pullout (Figure 10a) and fiber breakage, as well as matrix carking (Figure 10b). The fracture is ductile, as evidenced by the presence of pores in the matrix. A uniform corrosion attack may be used to attack the performance of such fiber-reinforced polymer (FRP) in a chlorine dioxide environment.

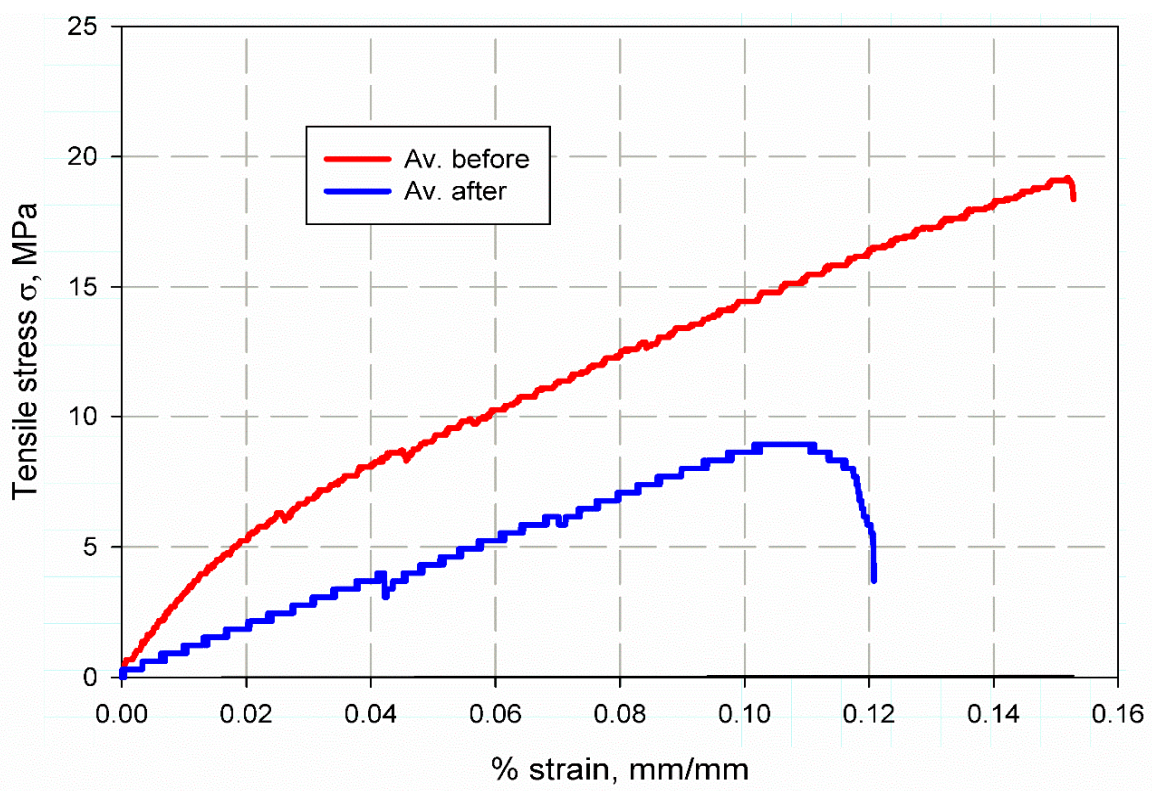

Figure 8. Effect of preconditioning on the stress and strain curves of composite pipes.

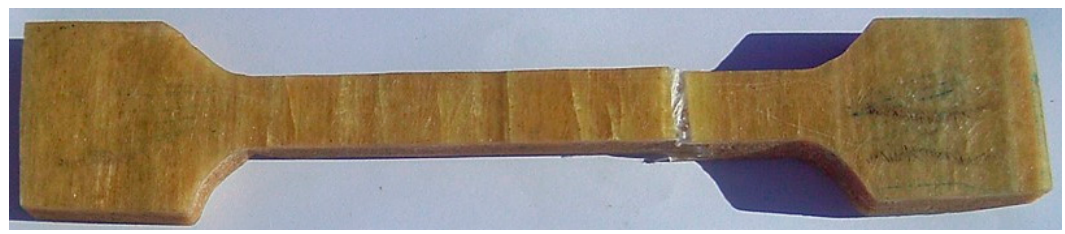

Figure 9. Tensile specimen fracture mode.

a)
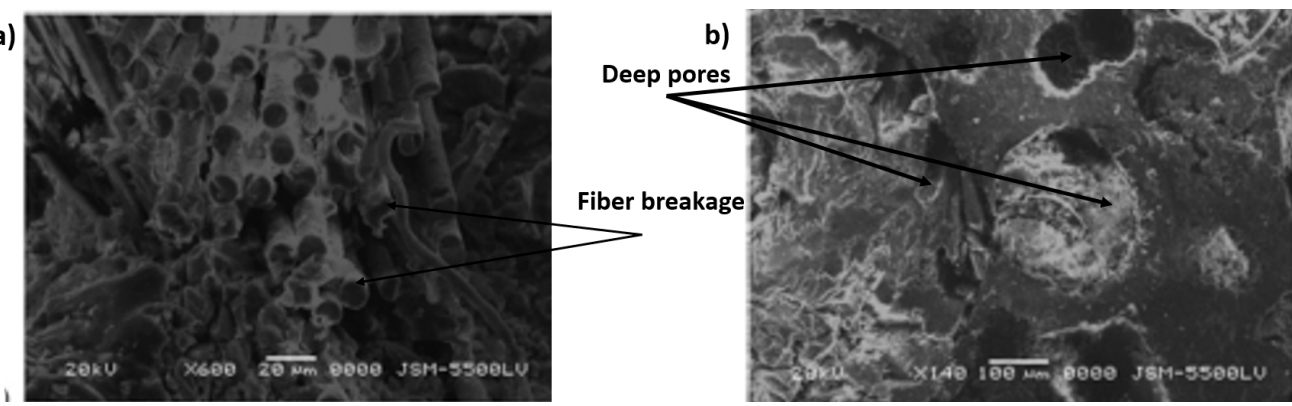

Figure 10. GRP SEM images: (a) fiber, (b) matrix.

As shown in Figure 11, the precondemning and corrosive agents affect the average compressive strength. A focus observation is made on the compressive behavior of glass fiber composite pipes in the transverse direction (see Figure 11a); it is discovered that there are two line slopes. Initially, the curve slope is nearly equal to $463.2 \mathrm{MPa}$ and $501 \mathrm{MPa}$ for after and before preconditioning in a chlorine dioxide solution, respectively, before changing to $1.4 \mathrm{GPa}$ and $1.2 \mathrm{GPa}$. This might be attributed to the compressive load being resisted at the first stage by the exterior and interior curved glass fiber layers. The curvature acts like a spring to overcome compressive stress. The entire specimen 
resists the compressive load after this curvature of the internal layer straightness over the compressive lower platen; thus, the slope and stiffness increase until failure occurs (see Figure 12a). After preconditioning, compressive strength drops by nearly 5.9 percent. Figure $11 \mathrm{~b}$ depicts the compressive stress and strain curve for compression loading in the longitudinal direction. It is demonstrated that the effect of preconditioning reduces compressive strength and young compressive modulus by nearly 21.5 percent, owing to the hygrothermal impact of moisture and the chemical reaction that occurs between chlorine gas CL and the polymer matrix [14]. Compressive stress steps correspond to the movement of quartz particles under compressive load; these steps were shifted back in the case of preconditioning, which could be attributed to the amount of water absorbed through the sand. Failure modes observed included serve damage and deeply cross cracks in the quartz phase, with no cracks in the exterior or interior layers. Delamination was also observed between glass fiber layers and quartz sand, which occurred because of the sand particles debonding from one another (see Figure $12 b$ ).

a)
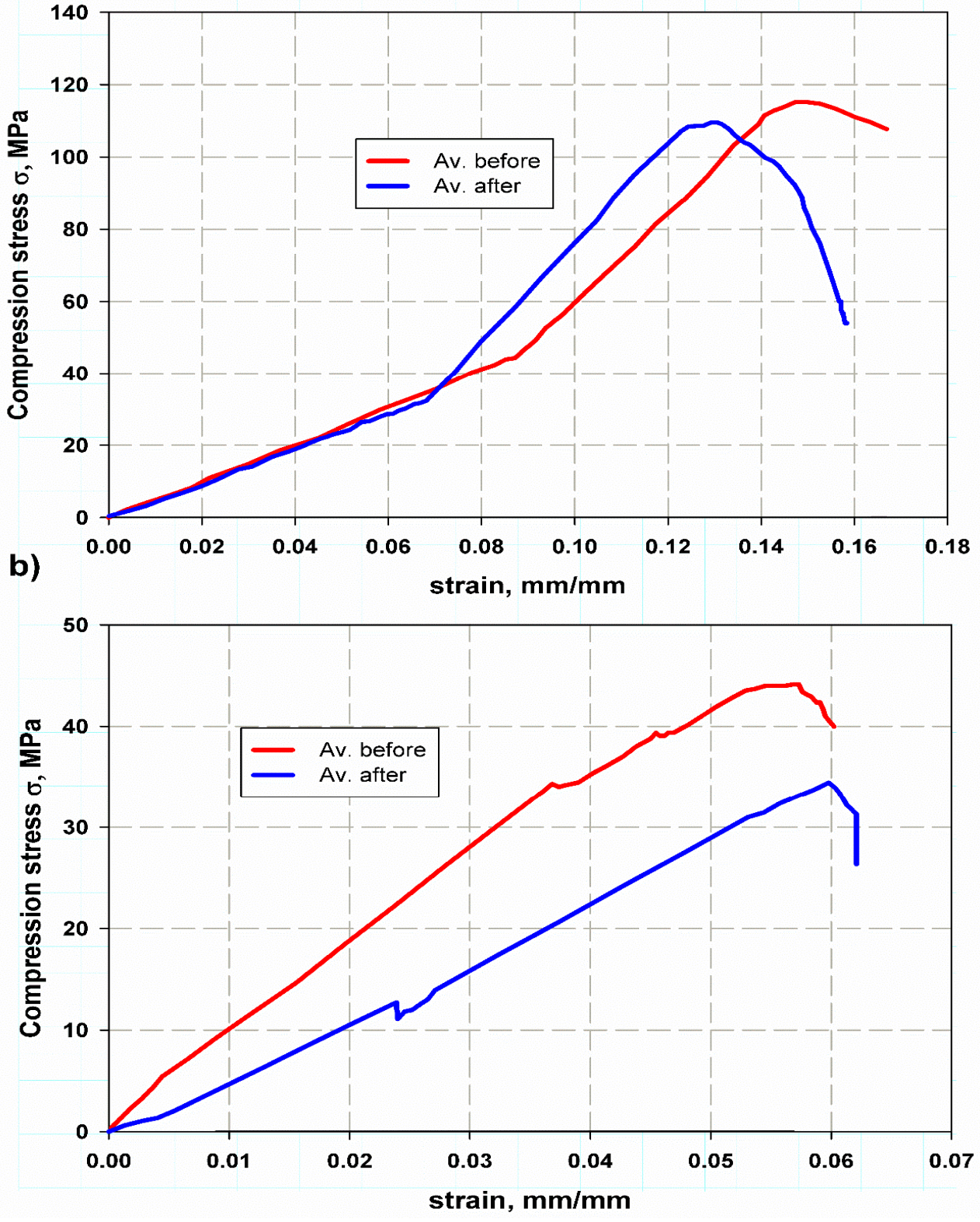

Figure 11. Composite pipe compressive behaviors; (a) transverse, (b) longitudinal. 

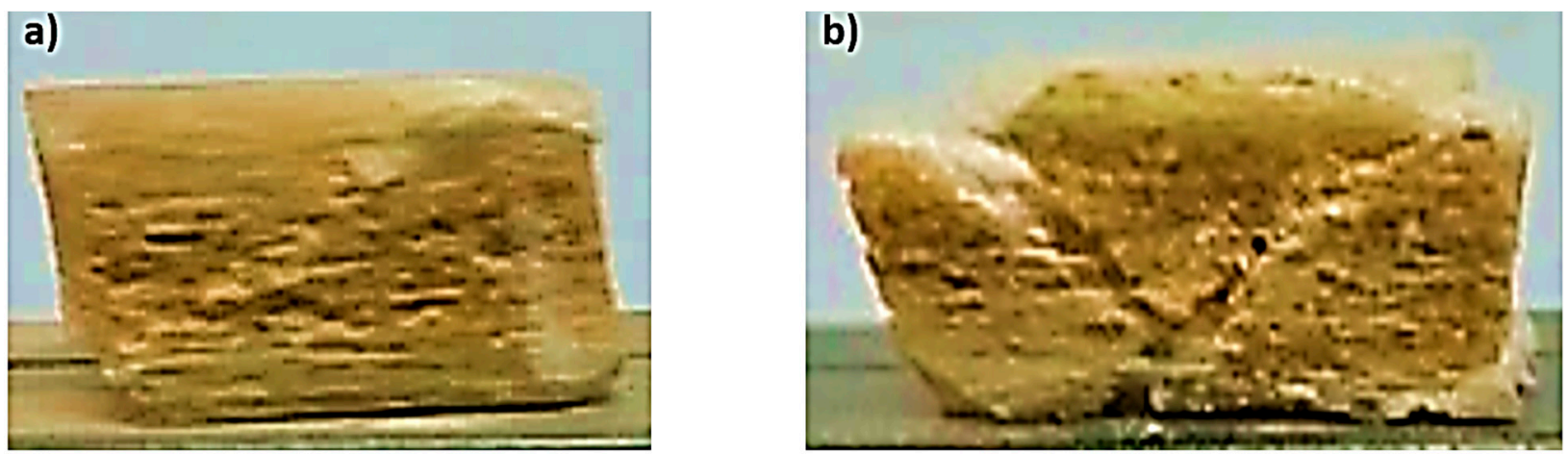

Figure 12. Compression failure mode; (a) transverse, (b) longitudinal.

Figure 13 depicts the load and displacement curve of a SENB specimen. It is observed that no softening occurred (red color line), and the curve was smooth, owing to the stress concentration near the blunt crack face, which is more sensitive. The load increases as the crack propagate through the material [32] due to the glass fiber layer resisting the load and the crack tip facing sand particles, which increases the crack tip and relieves stress; this explanation can be seen in the fracture mode. Figure 14 depicts the fiber bridging and the straight direction of the crack. When the maximum load $(\mathrm{P})$ is read and then entered Equation (1). The fracture toughness is $283.4 \mathrm{MPa} \sqrt{m}$ with a standard deviation of 21.5 MPa $\sqrt{m}$. The material fracture behavior changed dramatically (see blue line), as the behavior softened after the critical value was reached, then decreased as the crack propagated through the material. This can be attributed to the amount of corrosive water with chlorine gas deeply absorbed by the sand and reach with the polymer, resulting in weak debonding between the sand particles, resulting in a decrease in fracture toughness, which is measured at $182.5 \mathrm{MPa} \sqrt{\mathrm{m}}$. with a standard deviation of $15.5 \mathrm{MPa} \sqrt{\mathrm{m}}$. (red color line). This is because the second specimen's crack takes a long time to propagate through the material due to the high debonding strength between the particles, whereas the first specimen's debonding strength is low.

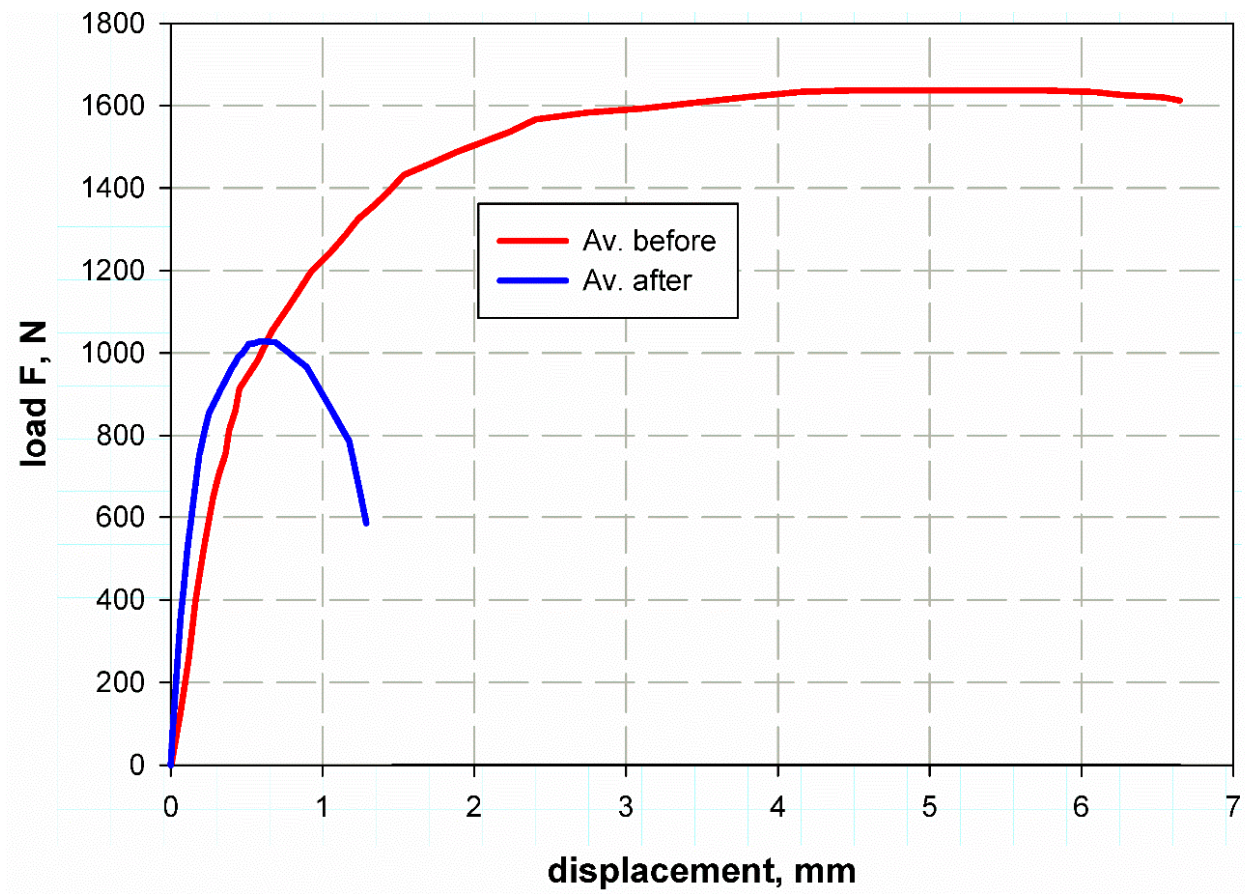

Figure 13. SENB specimen load-displacement curve. 


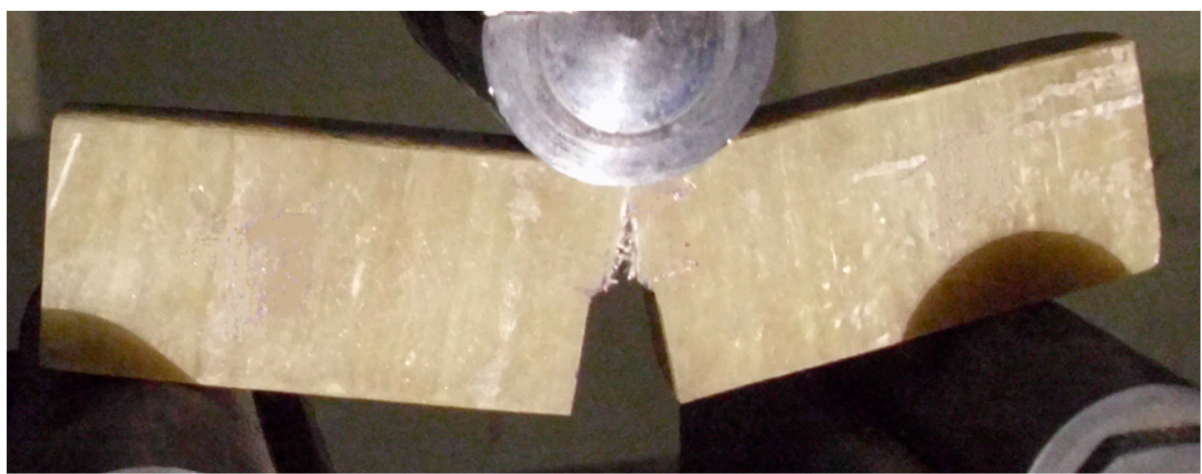

Figure 14. SENB's fracture mode.

\subsection{Charpy Impact Test}

The shape of the sample significantly influences the fracture toughness of existing materials during the impact test. After immersion in chemically wasted petroleum water, the loading of the sample is much lower (see Figure 15), and the material softens. In contrast, the sample before immersion solidifies, and the quartz particles can absorb water through the thickness. As a result, any fine cracks or crevices on the surface are magnified. The inside of the GRP pipes can cause water leakage on the quartz particles, resulting in dangerous degradation, as illustrated in Figure 15. The corrosion effect resulted in a deterioration between the sand and epoxy layers in a proportion of approximately $50 \%$, and Table 3 lists the impact toughness per joule before and after immersion.

Table 3. Impact energy of Charpy test.

\begin{tabular}{cc}
\hline Impact Toughness of Specimen & Unit (Joule) \\
\hline Before immersion in wastewater & 8.5 \\
\hline After immersion in wastewater & 5 \\
\hline
\end{tabular}
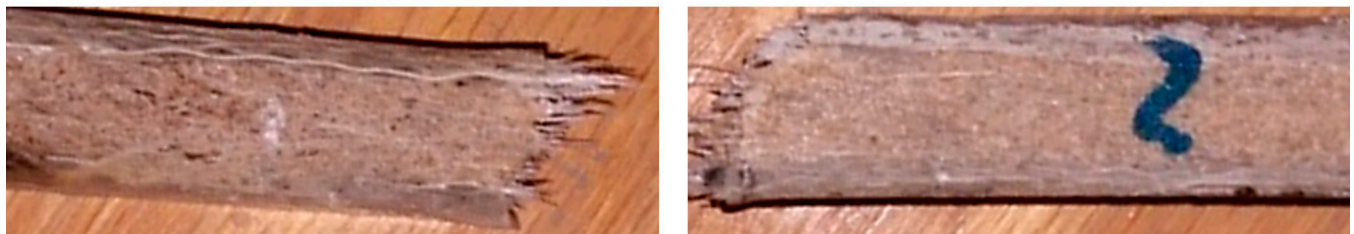

Figure 15. Within the photo of an impact fracture, the mode of failure can be seen.

\subsection{Ring Stiffness Characteristic}

Figure 16 depicts the initial ring stiffness of composite pipes, based on the values of three specimens from the experimental work of [24]. The average reaction force was $23 \mathrm{kN}$, while the FE analysis required $26.5 \mathrm{kN}$; thus, the prediction error was 15.2 percent, acceptable [38-41]. This error was a cumulative number of errors due to damage through used pipes, manufacturing defects, and so on. The numerical FE model assumes no delamination or damage between the glass fiber composites layers themselves or with the sand at interfaces, so the FE model data fit the initial portion of deflection very closely. As a consequence, the elastic behavior is prolonged until a sudden failure occurs. Moreover, this difference is most likely due to an incomplete adhesion in experimental specimens, resulting in higher stress concentration factors and premature failure [39]. Figure 17 depicts the stress distribution through the pipe wall; it is observed that a region of increasing stress concentration (red and orange color) around the crack (see Figure 17a,c), which corresponds to the fracture planes in experimental image Figure 17b [24], where surface cracks are located around the fracture plan. The precondemning affects the initial ring stiffness, as shown in Figure 16. (red dash lines). The hygrothermal effect of water 
absorption by the sand in the pipe's core reduces the strength of the pipe's material. The experimental findings will be used to validate the FE model.

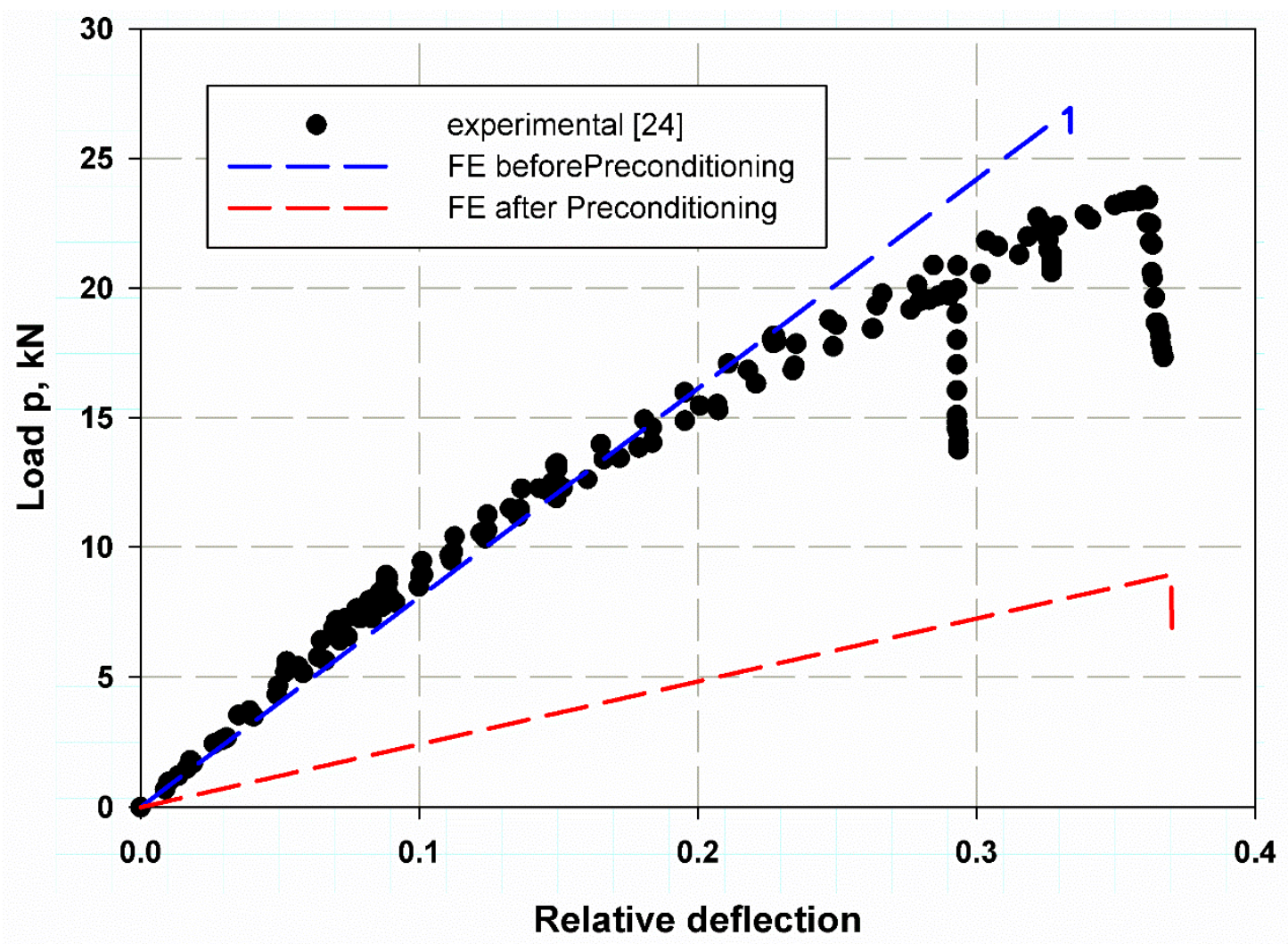

Figure 16. Validation of prediction ring stiffness load with experimental results of Ref. [24].

a)

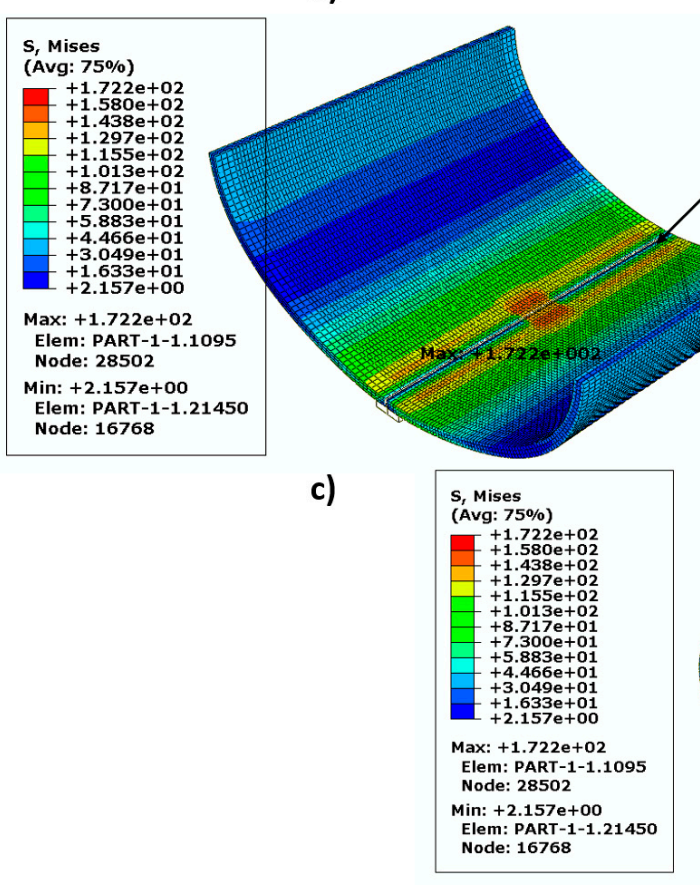

b)
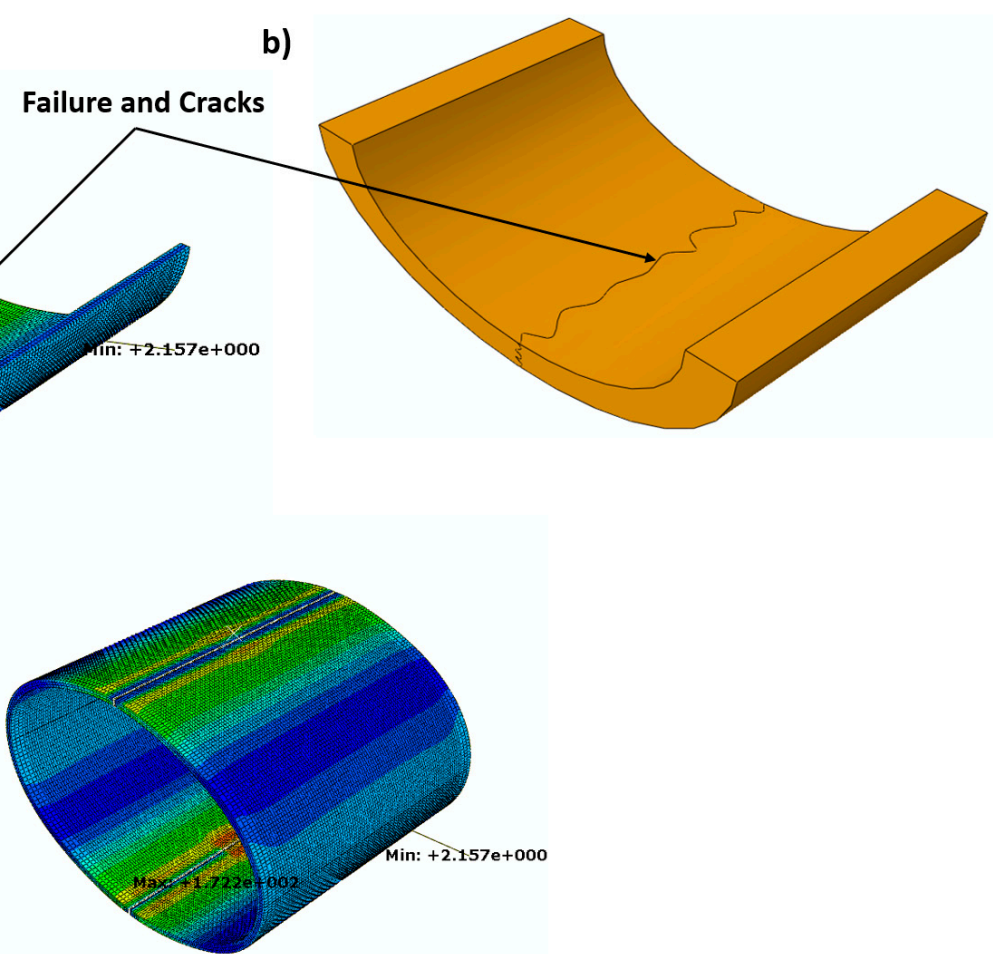

Figure 17. Failure mode prior to preconditioning; (a) FE prediction, (b) drawing based on experimental [24], (c) Von-Mises stress. 


\section{Conclusions}

The mechanical properties of glass fiber composite pipes and the initial ring stiffness were investigated before and after preconditioning in a petroleum wastewater chlorine dioxide corrosive solution. Pipes of this type are considered the primary infrastructure in the petroleum field industry. Current assessments show that the preconditioning action harms the mechanical properties studied, such as compression and tensile strengths. These pipes were typically subjected to preconditioning steps in the aggressive environment of the petroleum field while transporting wastewater saturated with corrosive chlorine dioxide, which is the primary cause of the material's high degradation. Furthermore, both dynamic and static fracture toughness are significantly reduced by this action. These corrosive solutions also affect the ring stiffness properties. The compressive strength of pipe wall material is considerably higher in the transverse direction than in the longitudinal direction.

Author Contributions: Conceptualization, M.Y.A., M.K.H., and A.F.M.; methodology, M.Y.A. and A.F.M.; software, M.Y.A. and M.K.H.; validation, K.A.K. and M.K.H.; formal analysis, M.Y.A., M.K.H., and K.A.K.; investigation, M.Y.A., M.K.H., and A.F.M.; resources, K.A.K.; writing—original draft preparation, M.Y.A., M.K.H., and A.F.M.; writing-review and editing, M.Y.A. and A.F.M.; supervision, M.K.H., and M.Y.A.; project administration, M.Y.A. and K.A.K.; funding acquisition, K.A.K. All authors have read and agreed to the published version of the manuscript.

Funding: This research was funded by the Saudi Basic Chemical Industries (SABIC) and the Deanship of Scientific Research at Umm Al-Qura University, Grant Code: (20-UQU-0071-DSR).

Acknowledgments: The authors would like to thank the Saudi Basic Chemical Industries (SABIC) and the Deanship of Scientific Research at Umm Al-Qura University for supporting this work by Grant Code: (20-UQU-0071-DSR).

Conflicts of Interest: The authors declare no conflict of interest.

\section{References}

1. Fukushima, K.; Cai, H.; Nakada, M.; Miyano, Y. Determination of time-temperature shift factor for long-term life prediction of polymer composites. In Proceedings of the ICCM-17, 17th International Conference on Composite Materials, Edinburgh, UK, 27-31 July 2009.

2. Plota, A.; Masek, A. Lifetime Prediction Methods for Degradable Polymeric Materials—A Short Review. Materials 2020, 13 , 4507. [CrossRef]

3. Julius, M.J. Time, Temperature and Frequency Viscoelastic Behavior of Commercial Polymers; West Virginia University: Morgantown, WV, USA, 2003.

4. Wang, J.Z.; Parvatareddy, H.; Chang, T.; Iyengar, N.; Dillard, D.A.; Reifsnider, K.L. Physical aging behavior of highperformance composites. Compos. Sci. Technol. 1995, 54, 405-415. [CrossRef]

5. Yao, J.; Ziegmann, G. Equivalence of moisture and temperature in accelerated test method and its application in prediction of long-term properties of glass-fiber reinforced epoxy pipe specimen. Polym. Test. 2006, 25, 149-157. [CrossRef]

6. Barbero, E.J.; Julius, M.J. Time-temperature-age viscoelastic behavior of commercial polymer blends and felt filled polymers. Mech. Adv. Mater. Struct. 2004, 11, 287-300. [CrossRef]

7. Feng, C.-W.; Keong, C.-W.; Hsueh, Y.-P.; Wang, Y.-Y.; Sue, H.-J. Modeling of long-term creep behavior of structural epoxy adhesives. Int. J. Adhes. Adhes. 2005, 25, 427-436. [CrossRef]

8. Chen, M. Accelerated Viscoelastic Characterization of E-Glass/Epoxy Composite. Ph.D. Thesis, Northwestern University, Evanston, IL, USA, 1991.

9. Goertzen, W.K.; Kessler, M. Creep behavior of carbon fiber/epoxy matrix composites. Mater. Sci. Eng. A 2006, 421, 217-225. [CrossRef]

10. Miyano, Y.; Nakada, M.; Sekine, N. Accelerated testing for long-term durability of FRP laminates for marine use. J. Compos. Mater. 2005, 39, 5-20. [CrossRef]

11. Farshad, M.; Necola, A. Effect of aqueous environment on the long-term behavior of glass fiber-reinforced plastic pipes. Polym. Test. 2004, 23, 163-167. [CrossRef]

12. Nishizaki, I.; Meiarashi, S. Long-term deterioration of GFRP in water and moist environment. J. Compos. Constr. 2002, 6, 21-27. [CrossRef]

13. Bergman, G. Managing corrosion on plastics-an analysis of experience from industrial applications. In Proceedings of the Corrosion-National Association of Corrosion Engineers Annual Conference, NACE, Orlando, FL, USA, $26-31$ March 2000.

14. Hojo, H.; Tsuda, K.; Kubouchi, M.; Kim, D.-S. Corrosion of plastics and composites in chemical environments. Met. Mater. 1998, 4, 1191-1197. [CrossRef] 
15. Farshad, M.; Necola, A. Strain corrosion of glass fibre-reinforced plastics pipes. Polym. Test. 2004, 23, 517-521. [CrossRef]

16. Stoia, D.I.; Marsavina, L.; Linul, E. Mode I Fracture Toughness of Polyamide and Alumide Samples obtained by Selective Laser Sintering Additive Process. Polymers 2020, 12, 640. [CrossRef]

17. Günöz, A.; Kepir, Y.; Memduh, K. The investigation of hardness and density properties of GFRP composite pipes under seawater conditions. Turk. J. Eng. 2022, 6, 34-39.

18. Shi, H.; An, Z.; Gao, R. Simulation of Mechanical Behavior and Structural Analysis of Glass Fiber Reinforced Mortar Pipes. Rev. Romana Mater. 2020, 50, 198-204.

19. Srinivasan, T.; Suresh, G.; Ramu, P.; Vignesh, R.; Vijay Harshan, A.; Vignesh, K.P. Effect of hygrothermal ageing on the compressive behavior of glass fiber reinforced IPN composite pipes. Mater. Today Proc. 2020, 45, 1354-1359. [CrossRef]

20. Abdellah, M.Y.; Hassan, M.K.; Alsoufi, M.S. Fracture and Mechanical Characteristics Degradation of Glass Fiber Reinforced Petroleum epoxy Pipes. J. Manuf. Sci. Prod. 2016, 16, 33-40. [CrossRef]

21. Seleem, A.-E.H.A. Failure and Corrosion Analysis of Composite Glass Fiber Reinforced Pipe Lines, in Mechaincal Engineering Department. Ph.D. Thesis, South Valley University, Qena, Egypt, 2015.

22. Abdellah, M.Y. Delamination Modeling of Double Cantilever Beam of Unidirectional Composite Laminates. J. Fail. Anal. Prev. 2017, 17, 1011-1018. [CrossRef]

23. Hassan, M.K.; Abdellah, M.Y.; Azabi, S.K.; Marzouk, W.W. Fracture Toughness of a Novel GLARE Composite Material. Int. J. Eng. Technol. 2015, 15.

24. Faria, H.Q.D. Failure Analysis of GRP Pipes under Compressive Ring Loads. Master's Thesis, Universidade do Porto, Porto, Portugal, 2005.

25. Standard, A. D3171-99. Standard Test Methods for Constituent Content of Composite Materials; ASTM International: West Conshohocken, PA, USA, 1999.

26. Abdellah, M.Y.; Alfattani, R.; Alnaser, I.A.; Abdel-Jaber, G.T. Stress Distribution and Fracture Toughness of Underground Reinforced Plastic Pipe Composite. Polymers 2021, 13, 2194. [CrossRef] [PubMed]

27. ASTM Standards. ASTM D3039/D3039M-17, Standard Test Method for Tensile Properties of Polymer Matrix Composite Materials; ASTM International: West Conshohocken, PA, USA, 1995; pp. 99-109.

28. ASTM Standards. D3410/D3410M-03. Standard Test Method for Compressive Properties of Polymer Matrix Composite Materials with Unsupported Gage Section by Shear Loading; ASTM International: West Conshohocken, PA, USA, 2008.

29. 100kN Computerized Universal Testing Machine. Available online: http://www.victorytest.com/products/wdw-50100computerized-electromechanical-universal-testing-machine/ (accessed on 8 June 2020).

30. Anderson, T.L.; McHenry, H.I.; Dawes, M.G. Elastic-Plastic Fracture Toughness Tests with Single-Edge Notched Bend Specimens, in Elastic-Plastic Fracture Test Methods: The User's Experience; ASTM International: West Conshohocken, PA, USA, 1985.

31. ASTM International. D5045-14. Standard Test Methods for Plane-Strain Fracture Toughness and Strain Energy Release Rate of Plastic Materials, Annual Book of ASTM Standards; ASTM International: West Conshohocken, PA, USA, 2014; Volume 8.

32. Chen, Z.; Adams, R.; da Silva, L.F. Fracture toughness of bulk adhesives in mode I and mode III and curing effect. Int. J. Fract. 2011, 167, 221-234. [CrossRef]

33. ASTM International. Standard Test Method for Determining the Charpy Impact Resistance of Notched Specimens of Plastics. ASTM D6110-10; ASTM International: West Conshohocken, PA, USA, 2010.

34. Belytschko, T.; Black, T. Elastic crack growth in finite elements with minimal remeshing. Int. J. Numer. Methods Eng. 1999, 45, 601-620. [CrossRef]

35. Melenk, J.M.; Babuška, I. The partition of unity finite element method: Basic theory and applications. Comput. Methods Appl. Mech. Eng. 1996, 139, 289-314. [CrossRef]

36. Datta, D. Introduction to eXtended Finite Element (XFEM) Method. arXiv 2013, arXiv:1308.5208.

37. Montasser Dewidar, N.S.K.; Mohammed, Y.; Abdellah Ayman, M.M. Finite element modeling of mechanical properties of titanium foam and dental application. In Proceedings of the Third International Conference on Energy Engineering (ICEE), Aswan, Egypt, 28-30 December 2015.

38. Khashaba, U. Tensile and flexural properties of randomly oriented gfrp composites. In 1st International Conference on Mechanical Engineering Advanced Technology for Industrial Production; Assiut University: Assiut, Egypt, 1994; Volume 1, pp. 131-143.

39. Berbinau, P.; Filiou, C.; Soutis, C. Stress and failure analysis of composite laminates with an inclusion under multiaxial compression-tension loading. Appl. Compos. Mater. 2001, 8, 307-326. [CrossRef]

40. Soutis, C.; Curtis, P. A method for predicting the fracture toughness of CFRP laminates failing by fibre microbuckling. Compos. Part A Appl. Sci. Manuf. 2000, 31, 733-740. [CrossRef]

41. Abdellah, M.Y. Comparative Study on Prediction of Fracture Toughness of CFRP Laminates from Size Effect Law of Open Hole Specimen Using Cohesive Zone Model. Eng. Fract. Mech. 2018, 191, 277-285. [CrossRef] 